\title{
Role of Multidetector Computed Tomography with Three Dimension Reconstruction in Evaluation of Pelvic Fractures
}

\author{
AHMAD A. ABD EL-GALEEL, M.Sc.; MOHAMMAD F. DAWOOD, M.D.; ALY A. EL-BARBARY, M.D. and \\ MOHAMMAD M. EL-ASHWAH, M.D.
}

The Department of Radio-Diagnosis \& Medical Imaging, Faculty of Medicine, Tanta University

\begin{abstract}
Background: Pelvic fracture is a serious injury that may be associated with high morbidity and mortality. MDCT is more frequently used for accurate evaluation of pelvic fractures.

Aim of Study: The aim of this work is to evaluate the role of multidetector CT with three dimension reconstruction in diagnosis of pelvic fractures.

Patients and Methods: This prospective study included 70 patients who presented with pelvic fractures and referred from outpatient clinics of Orthopedic Department to the Radiology and Medical Imaging Department, Tanta University Hospital. The present study was performed in the period between February 2018 and March 2019. Their ages ranged from 4 to 82 years; 45 of them were males and 25 were females. All cases underwent multidetector computed tomography as a rapid, noninvasive diagnostic tool, and the findings were compared with those of plain X-ray.

Results: According to our results patients with partial unstable pelvic ring fractures (Tile type B) had higher incidence than stable fractures $(54.28 \%)$, followed by stable Tile A fractures $(28.57 \%)$. Young Burgess lateral compression fractures had significantly higher incidence $(68.57 \%)$ especially Young Burgess subtype LC1 (54.28\%). All sacral fractures were associated with pelvic ring fratures, Denis zone I was the most common (54.28\%). The elementary Judet-Letournel acetabular fractures were the most common $(58.82 \%)$ especially type posterior wall $(20.58 \%)$. Hip dislocations and femur head fractures were rare, represented only by 4 cases for each. The most common hip dislocation type was the posterior dislocation represented only by 2 cases $(50 \%)$.
\end{abstract}

Conclusion: MDCT with 3D has numerous advantages and accurate in diagnosis of pelvic fratures.

Key Words: $M D C T-3 D-$ Pelvis - Fractures.

\section{Introduction}

THE term "pelvis" literally means a basin. It is made up of four bones: Two hip (innominate) bones, sacrum, and coccyx, bound to each other

Correspondence to: Dr. Ahmad A. Abd El-Galeel,

The Department of Radio-Diagnosis \& Medical Imaging, Faculty of Medicine, Tanta University by the ligaments. It supports the weight of the body and transmits it to the lower limbs successively through sacrum, sacroiliac joints, innominate bones, and then to femora in the standing position, and ischial tuberosities in the sitting position [1]

The majority of pelvic ring fractures are a result of a high energy injury, although many elderly patients may sustain such injuries from a fall from standing height. Motorcycle accidents Pelvic Ring Fractures and motor vehicle pedestrian accidents are the most common mechanisms, although falls, motor vehicle collisions, equestrian accidents, and crush injuries also occur [2].

Pelvic X-ray is a routine part of the primary survey of polytraumatized patients according to Advanced Trauma Life Support (ATLS) guidelines. However, pelvic CT is the gold standard imaging technique in the diagnosis of pelvic fractures [3] In most departments CT has replaced special radiographic projections with regard to classification of pelvic fractures [4].

$\mathrm{CT}$ is essential in the evaluation of complex fractures, particularly of the spine, pelvis, and scapula, although this modality is useful in the assessment of any fracture near or extending into the joint [5].

Fractures of the pelvis, and especially those involving the acetabulum, can be difficult to evaluate completely with plain film alone. CT scaning should be considered in almost all acetabular fractures because of the possibility of free fragments and subtle fractures that plain film don't show [6]

Three dimensional reformats may be requested for the purpose of assessing complex fracture characteristics or for assessing bone geometry to assist in pre-operative planning for arthrotomies or arthroplasties [7]. 
Three dimensional imaging should be obtained in every pelvic CT examination for pelvic trauma. Surface rendered images for scrolling in the axial and sagittal planes allow one to appreciate the full extent of pelvic injuries and are most helpful for treatment planning. Volume rendered transparencies should be obtained routinely a substitute for the additional radiographs (inlet, outlet, and obturator, and iliac obliques) that are often obtained [8].

\section{Patients and Methods}

The present study was performed in the Radiology and Medical Imaging Department, Tanta University Hospital at the period between February 2018 and March 2019. Study included 70 patients with pelvic fractrues, 45 of them were males and 25 were females. Their ages ranged between 4 and 80 years, and mean age 34 years. Road traffic acciedents were responsible for $84 \%$ (motor cycles $24 \%$, pedestrians $43 \%$, car accident $17 \%$ ), falling from height represented only $16 \%$.

According to age patients divided in 7 groups, Group I ( $<10$ years) 3 patients, Group II (11:20 years) 13 patients, Group III (21:30 years) 21 patients, Group IV (31:40 years) 11 patients, Group V (41:50 years) 10 patients, Group VI (51:60) years 6 patients, Group VII (>60 years) 6 patients.

Inclusion criteria: All patients with traumatic pelvic fractures were included.

Exclusion criteria: Patients with pathological pelvic fractures.

All the patients subjected to complete history taking to identify the cause, clinical examinations, privacy of participants and confidentially of the data, demonstration of benefits and risks to patient, any unexpected risks appeared during the examination cleared to patient.

All the patients subjected to plain radiography, AP view as routine view, and oblique views as special views for cases with acetabular fractures.

All the patients subjected to CT examination with CT scanner at Tanta University Hospital on (General Electric Optima 660), all patinets scanned in supine position with avoidance moving during examination, scout view of the pelvis with scanning started from the top of iliac crest and continue through the level of ischial tuberosities.

Scan parameters were $0.625-1.25 \mathrm{~mm}$ slice thickness, 0, 5-1 second rotation time, with 120 , $140 \mathrm{kVp}$ and maximum $330 \mathrm{~mA}$.
Examination include coronal, axial and sagittal multiplanar reformation for all patients to describe fractures of sacrum and acetabulum for all patients, creation of three dimensional volume rendering reconstruction from the CT data for all patients, $3 \mathrm{D}$ reconstruction with transparency logarithm, subtraction of femur head in cases with acetabular fractures.

Contrast studies include 21 patients were subjected to CT scanning immediately after IV injection of iopromide $62 \%$.

\section{Results}

Patients divided into 4 groups (Group I pelvic ring fractures group, Group II Acetablar fractures group, Group III sacral fractures, Group IV Hip dislocations and/or femur head dislocations).

Group I patients with pelvic ring fractures $(n=58)$ : In our study all pelvic ring fracture were associated with sacral fractures, but they were associated or not associated with acetabular fractures ( 22 cases were associated with acetabular fractures, 36 cases were not associated with acetabular fractures).

Group II patients with acetabular fractures $(n=33)$ : In our study acetabular fractures were associated or not associated with pelvic ring fractures ( 22 cases associated with pelvic ring fractures, 11 cases not associated with pelvic ring fractures), one case only was with different bilateral acetabular fractures (posterior column with posterior wall and posterior wall).

Group III patients with Sacral fractures $(\mathrm{n}=35)$ : All accompanied with pelvic ring fractures.

Group IV patients with hip dislocations $(n=4)$ and/or femur head fractures $(n=4)$ : Our study include 4 hip dislocations, 2 posterior hip dislocations, 1 central hip dislocation and 1 anterior hip dislocation. Also 4 cases with femur head fractures, one case only associated with posterior dislocation.

Table (1): Distribution of patients with pelvic ring fractures according to Young-Burgess classification, $(n=70)$.

\begin{tabular}{lccccc}
\hline Types & Subtypes & $\mathrm{n}$ & $\%$ & Total.n Total \% \\
\hline Unclassified & & & & 12 & $17.14 \%$ \\
Anteroposterior compression & I & 5 & 7.14 & 6 & $8.57 \%$ \\
& II & 1 & 1.42 & & \\
& III & & & & \\
Lateral compression & I & 38 & 54.28 & 48 & $68.57 \%$ \\
& II & 6 & 8.57 & & \\
Vertical shear & III & 4 & 5.71 & & \\
Combined mechanical injury & & 3 & & 3 & $4.28 \%$ \\
\hline
\end{tabular}




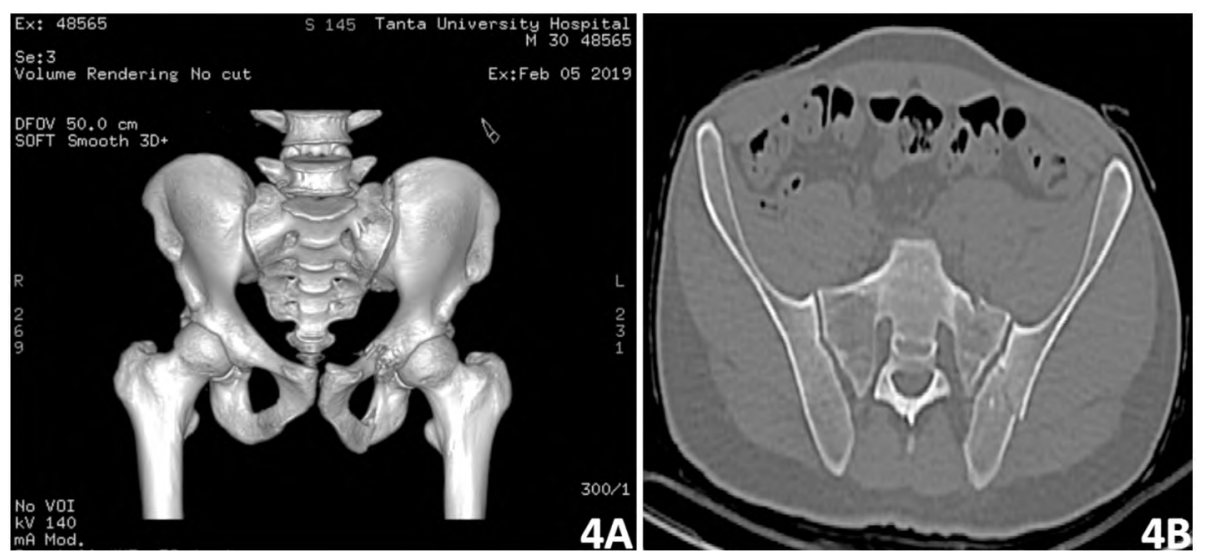

Fig. (4): (A) 3D CT, AP view of 30 year old male pelvis showing fractures of the left superior and inferior pubic ramus, posterior left iliac wing fracture, left side sacral fracture, classified as AO/OTA 61B2.2, Denis zone II. (B) Axial CT showing crescent fracture of the left iliac wing, left side sacral fracture.

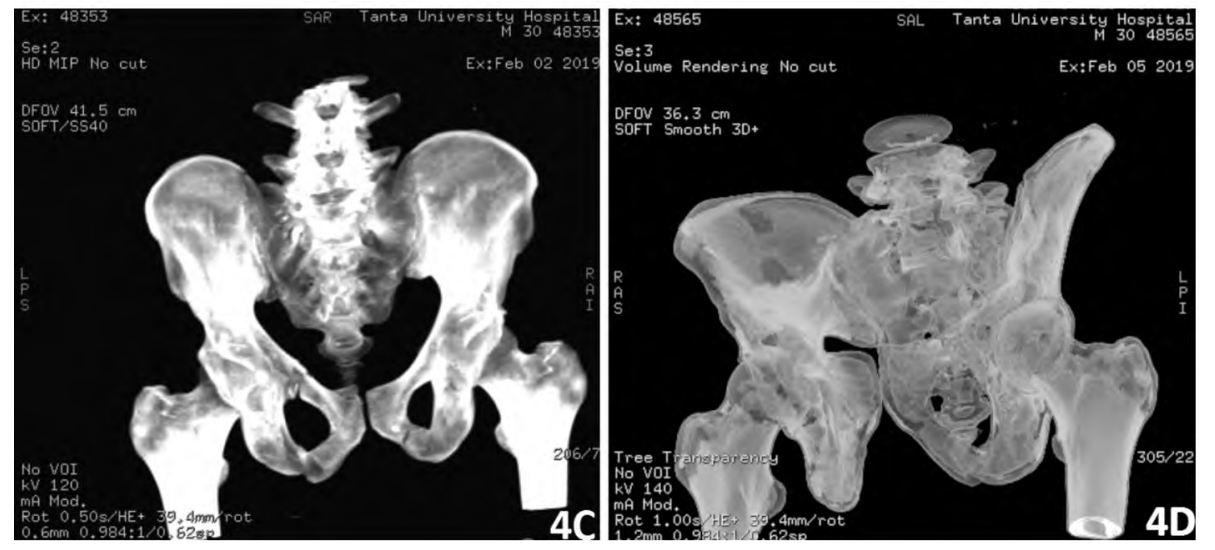

Fig. (4): (C,D) 3D CT with transparency showing the same fractrures except right inferior pubic ramus fracture is best visualized in Fig. (4C).
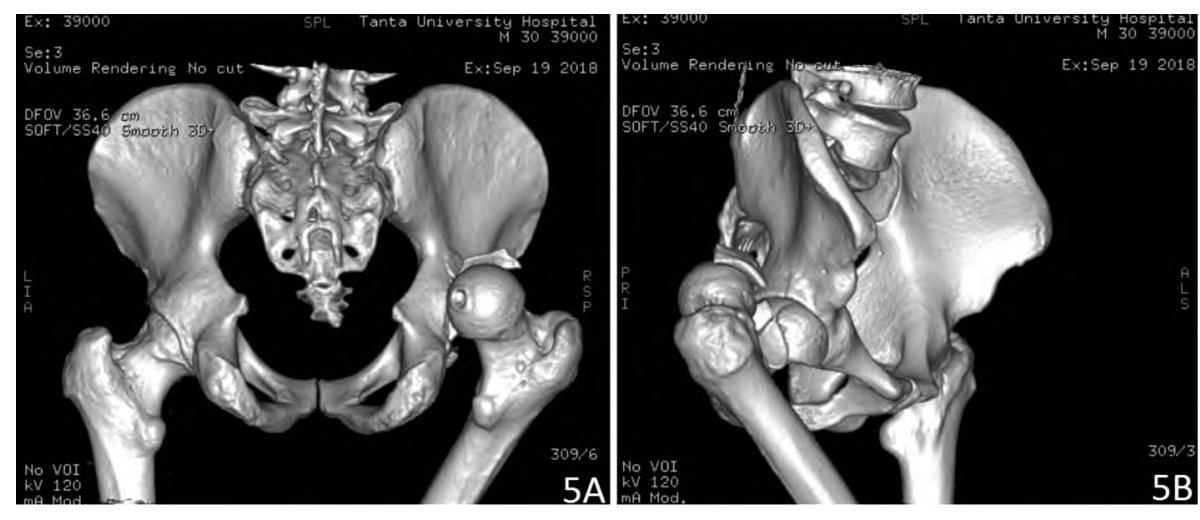

Fig. (5): (A) 3D CT, PA view of 30 year old male pelvis showing the posterior dislocation of right femur head, classified as Thompson and Epstein type III. (B): 3D CT, oblique view showing the posterior dislocation of right femur head and fracture of posterior wall of right acetabulum.

\section{Discussion}

In the present study males were more than females and road traffic accidents were the most common cause of pelvic fractures.

In accordance with our finding, Keykhosro Mardanpour, et al., [9] and Gilberto José, et al.,
[10] stated that males were affected more than females and road traffic accidents were the most common cause of pelvic fractures, followed by fall from a height.

Subhajit Ghosh, et al., [11] stated that Pelvic fractures and injuries were more often verified 
among males and young adults. Traffic accidents were the most common cause of the injury.

Plain radiographic results is compared with those of CT, CT shows superiority in the diagnosis of all pelvic fracture types especially in diagnosis of sacral and acetabular fractures.

We used 5 systems to classify pelvic ring fracture and they were as the following, (Tile classification, Young-Burgess classification, Key Conwell classification, AO/OTA classification and Torode Zeig classification to classify pediatric patients only).

The most widely used classifcation scheme today is that of Young and Burgess This classifcation is based on the mechanism of injury. There are four types described: Lateral Compression (LC I-III), Anterior-Posterior Compression (APC I-III), Vertical Shear (VS), and Combined Mechanism (CM). Lateral compression injuries are the most common pattern encountered. These result from side impact injuries such as in motor vehicle collisions [2].

According to Young-Burgess classification lateral compression type LC was the most common type followed by the Anteroposterior compression, vertical shear Fig. (3A,B) and combined mechanical injury. Subtype LC1 were the most common followed by subtype LC2 Fig. (4). Patients with isolated acetabular fractures $(n=8)$, avulsions, isolated iliac wing fractures $(n=4)$ unclassified by this system $(n=12)$.

In accordance with our results Ashok Vidyarthi, et al., [12] stated that type LC, and subtype LC 1 were the most common.

The tile classifcation is divided into three types: A, B, and C. Type A injuries (A1, A2) are stable and can be managed non operatively. Type B injuries (B1-3) include rotationally unstable injuries that are vertically stable. The type $\mathrm{C}$ injury (C13 ) is both rotationally and vertically unstable. This classifcation scheme aids in the understanding of the stability of each pelvic ring fracture and the need for surgical intervention [2]

According to tile classification $13(n=70)$ we classified patients with pelvic ring fractures into 3 types A, B, C with three subtypes in B and C and two subtypes in A. The most common type was type B $(54.28 \%)$, followed by type A $(28.57 \%)$ and type $\mathrm{C}(5.71 \%)$ Fig. (3A,B). The most common subtype was B2 Fig. (4), 8 patients with isolated acetabular fracture unclassified by this system (11.42\%).
In accordance with our findings Erik Hermans, et al., [14] stated that type B and subtype B2 were the most common. Akbar B Tilyakov, et al., [15] stated that type B was the most common type.

The comprehensive classifcation developed by Helfet combines the AO/OTA Fracture and Dislocation Classifcation system of fracture with the tile classifcation based on the concept of stability of the pelvis. Through the subgroups and qualifcations, the comprehensive classifcation also incorporates anatomy of the pelvic ring and the concepts of mechanism of injury [16]

Based on AO classification, the location code for the pelvic ring is the number " 61 ." According to the mechanism of injury, fracture location, and the stability of the pelvis, the segment 61 fractures can be further divided into: 61- A: Posterior arch intact, stable; 61-B: Incomplete posterior arch disruption, partially stable; and 61-C: Complete posterior arch disruption, unstable [17]

According to AO/OTA [18] we classified patients with pelvic ring fractures into 3 types $A, B, C$ and each with three groups, each group with 3 subgroups except group 61A3.

According to our study type 61B was the most common, and also group $61 \mathrm{~B} 2$ was the most common group.

Key and Conwell's classifcation of pelvic fractures in adults is based on the number of breaks in the pelvic ring. Their system, which includes acetabular fractures, also is applicable in children [19].

According to Key and Conwell's classification $(n=70)$, we classified patients with pelvic fractures into 4 types. The most common type was type III $(37.14 \%)$ Figs. $(3,4)$ followed by type IV $(30 \%)$, type II $(20 \%)$ and type I $(1.42 \%), 8$ patients with isolated acetabular fracture unclassified by this system (I1.42\%).

Numerous classifcation systems have been devised for pelvic fractures in children. The most widely used classifcation was proposed by Torode and Zieg and describes a four part classifcation of pelvic fractures: Type I, avulsion of the bony elements of the pelvis; type II, iliac wing fractures; type III, simple ring fractures, including fractures involving the pubic rami or disruptions of the pubic symphysis; and type IV, including unstable injuries [19].

According to Torode and Zieg classification $(n=12)$, we classified pediatric patients with pelvic 
fractures into 4 types, the most common was type IV ( 7 cases), followed by type III ( 5 cases).

We used 2 systems to classify the acetabular fractures (Judet-Letournel and AO/OTA systems).

The classification method of Letournel and Judet is the most widely used classification of acetabular fractures in clinical practice and research. It classifies acetabular fractures into two basic types: Simple fracture patterns and complex fracture patterns. Simple fracture patterns belong to a group of fractures in which only a wall or column is fractured, while complex patterns are combinations of the simple patterns [17]

According to Judet and Letournel classification we classified patients with acetabular fractures into 5 elementary types and 5 associated types. The five elementary types include anterior wall, posterior wall, anterior column, posterior column and transverse acetabular fractures. The five associated types include posterior column with posterior wall, anterior column with posterior hemitransverse, Tshape fractures and transverse with posterior wall and both column fractures.

According to our study elementary acetabular fractures group $(n=20)$ had higher incidence than associated acetabular fractures group $(n=14)$, the most common type was the posterior wall fractures $(n=7)$.

In accordance with our results Cyril Mauffrey, et al., [20] stated that posterior wall fracture was the most common type.

Müller et al., integrated the Letournel classification into their standardized and complete AOsystem $[4,5,23]$. The resulting AO/OTA classification added additional relevant prognostic injuries of the hip joint, such as marginal impaction zones, femoral head injuries, and comminution zones into this "new" comprehensive classification system of acetabular fractures (Comprehensive Classification of Fractures $[\mathrm{CCF}]=\mathrm{AO} / \mathrm{OTA}$ classification). The main principle is a hierarchical classification of all fractures in triple groups [21].

According to AO/OTA [18] we classified patients with acetabular fractures into 3 types A, B, C, each with 3 groups, and each group divided into 3 subgroups except type $\mathrm{C}$ groups.

According to our results the most common type was $62 \mathrm{~A}$, the most common group was $62 \mathrm{~B} 1$.

Sacral fractures are most commonly classified by the system described by Denis. It categorizes the fractures based on the fracture line orientation and location with respect to the sacral foramina. Vertical or oblique fractures that occur just lateral to the sacral foramina are considered Zone I fractures this is the most common pattern, comprising almost $50 \%$ of injuries [2]

According to Denis classification we classified patients with sacral fractures into 3 types (Zone I, II, III). According to our results the most common type was zone I $(n=19)$, followed by zone II $(n=9)$ and zone III $(n=7)$.

Our study include 4 hip dislocations, two posterior hip dislocations, 1 central hip dislocation and 1 anterior hip dislocation. Also 4 patients with head fractures, one only associated with posterior dislocation.

There are three main types of dislocations of the hip: (I) Posterior dislocation (the commonest); (II) Anterior dislocation; (III) Central fracture dislocation. All of these may be associated with fracture of the lip of the acetabulum [22]

In our study we used Epstein system to classify anterior hip dislocation, Thompson and Epstein sysytem to classify posterior hip dislocations, Pipkin classification to classify femoral head fractures with posterior dislocations.

Thompson and Epstein have further classifed the posterior dislocation of the hip into four types and Pipkin has given four subclassifcations for the femoral head fracture in type IVB fracture of the Thompson and Epstein variety [23]. Most authors have used Pipkin's classification since its publication [24]. According to the classification presented by Thompson and Epstein in 1951, posterior hip dislocations are classified based on the presence, topography and severity of associated fractures [25].

According to Thompson and Epstein classification we classified posterior dislocations into 5 types. Our study include two cases only with posterior hip dislocation classified as type III and type IV. One case only associated with femur head fracture and acetabular fracture classified according to Pipkin classification as type IV. Posterior dislocations represent $50 \%$ of our dislocations cases $(n=2)$.

In accordance with our results Luciana Cascão, et al., [26] stated that posterior hip dislocations are the most common. 
Anterior hip dislocations are classified based on the head/acetabulum relationship and by the presence of associated fractures [25]

According to Epstein classification we classified anterior dislocations into 2 types each with three subtypes A, B, C. Our study include 1 case only with anterior dislocation classified as type IC.

$3 \mathrm{D}$ reformatted images obtained in all cases and it helps us to determine the full extent of pelvic injuries, and to assess complex pelvic fractures.

$3 \mathrm{D}$ reconstruction with transparency was done to create images that effectively simulate radiographic projections, some fracture gaps revealed better by it Fig. (4C, D).

Femoral head subtraction performed for visualization of the surface of acetabulum.

\section{Conclusion:}

MDCT has numerous advantages and accurate in diagnosis of pelvic fractures. It's the best choice for polytrauma patients and better than plain xray in diagnosis of pelvic fractures especially in diagnosis of subtle, acetabular and sacral fractures.

$3 \mathrm{D}$ volume rendering produces high quality images. It helps in better assessment of acetabular, sacral, complex fractures.

\section{References}

1- SINGH and VISHRAM: Textbook of Anatomy Abdomen And Lower Limb. 2nd ed., Reed Elsevier, p. 202, 2014.

2- COURT-BROWN, CHARLES M., et al.: Rockwood and Green's Fractures in Adults Vol 1. 8 th ed., Wolters Kluwer, pp. 1796-890, 2015.

3- HILTY, MATTHIAS P., et al.: "Pelvic Radiography in ATLS Algorithms: A Diminishing Role?" World Journal of Emergency Surgery, Vol. 3, No. 1, p. 11. Springer Nature, doi: 10.1186/1749-7922-3-11, 2008.

4- JURIK A.G., et al.: "Total Effective Radiation Dose From Spiral CT and Conventional Radiography of the Pelvis with Regard to Fracture Classification". Acta Radiologica, Vol. 37, No. 3P2, pp. 651-4. SAGE Publications, doi: 10.1177/02841851960373p246, 1996.

5- GREENSPAN, ADAM and JAVIER BELTRAN: Orthopedic Imaging A Practical Approach. 6 th ed., Wolters Kluwer, p. 111, 2016.

6- BRANT, WILLIAM and CLYDE HELMS: Fundamentals of Diagnostic Radiology. 4 th ed., Lippincott Williams And Wilkins, p. 1034, 2012.

7- McKINNIS and LYNN N.: Fundamentals of Musculoskeletal Imaging. 4th ed., F.A Davis Company, p. 370, 2014

8- ROGERS, LEE, and CLARK WEST: Imaging Skeletal Trauma. 4th ed., Saunders, p. 133, 2015.
9- MARDANPOUR, KEYKHOSRO, et al.: "Incidence of Pelvic Trauma and Relative Risk Factors for Mortality: A Population Based Study in Iran". Clinical Practice. OMICS Publishing Group, doi: 10.4172/clinical-practice. 1000401, 2018.

10- PEREIRA, GILBERTO JOSÉ CAÇÃO, et al.: "Epidemiology of Pelvic Ring Fractures and Injuries". Revista Brasileira De Ortopedia (English Edition), Vol 52, No. 3, pp. 260-9. Georg Thieme Verlag KG, doi: 10.1016/ j.rboe.2017.05.012, 2017.

11- SUBHAJIT GHOSHGHOSH, SUBHAJIT, et al.: "Epidemiology of Pelvic Fractures in Adults: Our Experience at A Tertiary Hospital". Chinese Journal of Traumatology, Vol. 22, No. 3, pp. 138-41. Elsevier BV, doi: 10.1016/ j.cjtee.2019.03.003, 2019.

12- VIDYARTHI, Dr. ASHOK and DEVENDRA NAYAK "Study of Incidence and Prevalence of Pelvic Fractures in Central India". Journal of Medical Science and Clinical Research, Vol. 6, No. 3, pp. 846-53. Valley International, doi: 10.18535/jmscr/v6i3.141, 2018.

13- TILE M.: "Pelvic Ring Fractures: Should They Be Fixed?". The Journal of Bone and Joint Surgery. British Volume Vol. 70, No. 1, pp. 1-12. British Editorial Society of Bone \& Joint Surgery, Doi: 10.1302/0301-620x.70b1.3276697, 1988.

14- HERMANS, ERIK, et al.: "Epidemiology of Pelvic Ring Fractures in A Level 1 Trauma Center in the Netherlands". Hip \& Pelvis, Vol. 29, No. 4, p. 253. The Korean Hip Society (KAMJE), doi: 1 0.5371/hp.2017.29.4.253, 2017.

15- TILYAKOV, AKBAR, et al.: "Clinical Outcomes of Pelvic Fractures in Uzbekistan". Biomedical Research, Vol. 26, No. 2, pp. 207-13, 2015.

16- TILE, MARVIN, et al.: Fractures of the Pelvis and Acetabulum. 4th ed., AO, p. 52, 2015.

17- ZHANG, YINGZE, et al.: Clinical Epidemiology of Orthopaedic Trauma. Thieme, pp. 327-86, 2012.

18- MEINBERG E.G., et al.: "Fracture and Dislocation Classification Compendium-2018". Journal of Orthopaedic Trauma, Vol. 32, pp. S71-S82. Ovid Technologies (Wolters Kluwer Health), doi: 10.1097/bot.0000000000001063, 2018.

19- AZAR, FREDERICK, et al.: Campbell's Operative Orthopaedics. 13 th ed., Elsevier, pp. 1477-82, 2017.

20- MAUFFREY, CYRIL, et al.: "The Epidemiology and Injury Patterns of Acetabular Fractures: Are the USA and China Comparable?". Clinical Orthopaedics and Related Research $®$, Vol. 472, No. 11, pp. 3332-7. Ovid Technologies (Wolters Kluwer Health), doi: 10.1007/s11999-0143462-8, 2014

21- GÄNSSLEN, AXEL, et al.: Acetabular Fractures. Thieme, p. 41, 2018.

22- MHASKAR, VIKRAM and J. MAHESHWARI: Essential Orthopaedics. 5 th ed., Jaypee the Health Science Publishers, p. 130, 2015.

23- EBNEZAR, JOHN and RAKESH JOHN: Textbook of Orthopedics. 5 th ed., Jaypee the Health Science Publishers, p. 199, 2017.

24- BROWNER, BRUCE D., et al.: Skeletal Trauma. 5 th ed., Saunders, pp. 1611, 2015. 
25- LASANIANOS, NICK G., et al.: Trauma and Orthopaedic

Classifications. Springer-Verlag, pp. 293-8, 2015.

26- LIMA, LUCIANA CASCÃO, et al.: "Epidemiology of
Traumatic Hip Dislocation in Patients Treated in Ceará, Brazil". Acta. Ortopédica Brasileira, Vol. 22, No. 3, pp. 151-4. Fapunifesp (Scielo), doi: 10.1590/1413-785220 14220300883, 2014.

\section{دور الآشعة المقطعية متعددة الكواشف مع التصوير معاد التشكيل

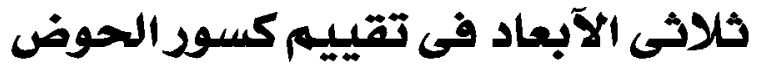

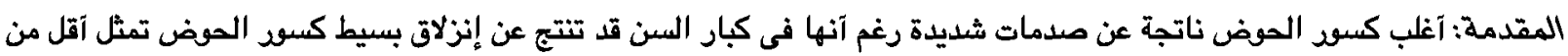

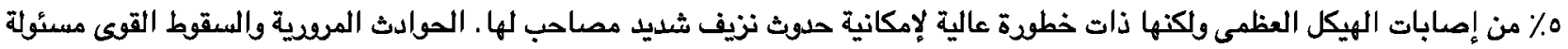
عن آغلب إصابات الصوض.

بالرغم من آن آشعة إكس هى فحص آولى لمتعدىى الإصابات طبقاً لتوجيهات الدعم المتقدم لصياة المصابين بالصدمات لكنها لا يمكنها الكشف عن إصابات الآنسجة الرخوة لذلك تعد الآشعة المقطعية معيار تصوير ذهبى لتشخيص كسود الصوض. فوقد حلت الآشعة المقطعية مكان

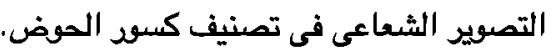

الفرض من البحث: تقييم دور الآثعة المقطعية متعدة الكواشف بإستخدام التصوير معاد التشكيل ثلاثى الآبعاد فى تشخيص كسود الصوض.

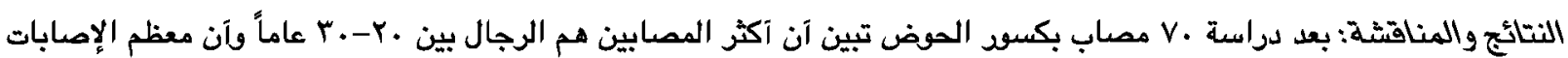

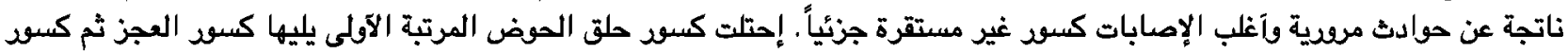

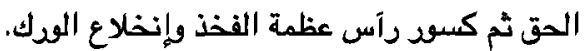

الإستتاج: الآشعة المقطعية متعددة الكواشف دقيقة ولها العديد من المزايا في تشخيص كسى الحوض. وهى الإختيار الآنسب لمتعددى الإيى الإصابات وآفضل من الآشعة العادية فى تشخيص كسو الموض خاصة الكسود الخفية وكسود الحق والعجز.

التصوير الحجمى ثلاثى الآبعاد معاد التشكيل ينتج صود عالية الجودة ويساعد فى تقييم آفضل لكسود الحق والعجز والكسود المركية. 